\title{
Machine learning applied to neuroimaging for diagnosis of adult classic Chiari malformation: role of the basion as a key morphometric indicator
}

\author{
Aintzane Urbizu, PhD, ${ }^{1,2}$ Bryn A. Martin, PhD, ${ }^{3}$ Dulce Moncho, MD, PhD, ${ }^{4,5}$ Alex Rovira, MD, ${ }^{6}$ \\ Maria A. Poca, MD, PhD, , Juan Sahuquillo, MD, PhD, , ${ }^{5,7}$ Alfons Macaya, MD, PhD, ${ }^{2}$ and \\ Malena I. Español, $\mathrm{PhD}^{8}$ \\ ${ }^{1}$ Conquer Chiari Research Center and ${ }^{8}$ Department of Mathematics, The University of Akron, Ohio; ${ }^{3}$ Department of Biological \\ Engineering, University of Idaho, Moscow, Idaho; and ${ }^{2}$ Pediatric Neurology Research Group, ${ }^{4}$ Department of Clinical \\ Neurophysiology, ${ }^{5}$ Neurotraumatology and Neurosurgery Research Unit, ${ }^{6}$ Magnetic Resonance Unit (IDI), Department of \\ Radiology, and 'Department of Neurosurgery, Vall d'Hebron Research Institute, Vall d'Hebron University Hospital, Universitat \\ Autònoma de Barcelona, Spain
}

\begin{abstract}
OBJECTIVE The current diagnostic criterion for Chiari malformation Type I (CM-I), based on tonsillar herniation (TH), includes a diversity of patients with amygdalar descent that may be caused by a variety of factors. In contrast, patients presenting with an overcrowded posterior cranial fossa, a key characteristic of the disease, may remain misdiagnosed if they have little or no $\mathrm{TH}$. The objective of the present study was to use machine-learning classification methods to identify morphometric measures that help discern patients with classic $\mathrm{CM}$-I to improve diagnosis and treatment and provide insight into the etiology of the disease.
\end{abstract}

METHODS Fifteen morphometric measurements of the posterior cranial fossa were performed on midsagittal T1weighted MR images obtained in 195 adult patients diagnosed with CM. Seven different machine-learning classification methods were applied to images from 117 patients with classic $\mathrm{CM}-\mathrm{I}$ and 50 controls matched by age and sex to identify the best classifiers discriminating the 2 cohorts with the minimum number of parameters. These classifiers were then tested using independent $\mathrm{CM}$ cohorts representing different entities of the disease.

RESULTS Machine learning identified combinations of 2 and 3 morphometric measurements that were able to discern not only classic CM-I (with more than $5 \mathrm{~mm} \mathrm{TH}$ ) but also other entities such as classic $\mathrm{CM}$-I with moderate $\mathrm{TH}$ and $\mathrm{CM}$ Type 1.5 (CM-1.5), with high accuracy (> 87\%) and independent of the TH criterion. In contrast, lower accuracy was obtained in patients with CM Type 0 . The distances from the lower aspect of the corpus callosum, pons, and fastigium to the foramen magnum and the basal and Wackenheim angles were identified as the most relevant morphometric traits to differentiate these patients. The stronger significance $(p<0.01)$ of the correlations with the clivus length, compared with the supraoccipital length, suggests that these 5 relevant traits would be affected more by the relative position of the basion than the opisthion.

CONCLUSIONS Tonsillar herniation as a unique criterion is insufficient for radiographic diagnosis of CM-I, which can be improved by considering the basion position. The position of the basion was altered in different entities of $\mathrm{CM}$, including classic $\mathrm{CM}-\mathrm{I}$, classic $\mathrm{CM}-\mathrm{I}$ with moderate $\mathrm{TH}$, and $\mathrm{CM}-1.5$. The authors propose a predictive model based on 3 parameters, all related to the basion location, to discern classic CM-I with $90 \%$ accuracy and suggest considering the anterior alterations in the evaluation of surgical procedures and outcomes.

https://thejns.org/doi/abs/10.3171/2017.3.JNS162479

KEY WORDS MRI; machine learning; Chiari malformation; basion; skull base

ABBREVIATIONS CM = Chiari malformation; $\mathrm{DT}=$ decision tree; $\mathrm{FM}=$ foramen magnum; $\mathrm{k}-\mathrm{NN}$ = $\mathrm{k}$-nearest neighbors; $\mathrm{LR}=$ logistic regression; $\mathrm{NB}=$ naïve $\mathrm{Bayes} ; \mathrm{PCF}=$ posterior cranial fossa; $\mathrm{SVM}=$ support vector machine; $\mathrm{TH}=$ tonsillar herniation.

SUBMITTED October 6, 2016. ACCEPTED March 30, 2017.

INCLUDE WHEN CITING Published online October 20, 2017; DOI: 10.3171/2017.3.JNS162479. 
$\mathrm{C}$ HIARI malformations (CMs) have traditionally been defined as entities in which there is either herniation of the posterior cranial fossa $(\mathrm{PCF})$ content below the foramen magnum (FM) - as in CM Type I (CMI), CM Type II (CM-II), and CM Type III (CM-III)-or hypoplasia of the cerebellum-as in CM Type IV (CMIV)-within a reduced PCF., ${ }^{9,10}$ In more recent years, 2 additional $\mathrm{CM}$ entities have been proposed: CM Type 0 (CM-0) and CM Type 1.5 (CM-1.5). ${ }^{22,48}$ However, the exact relevance and distinctiveness of each of these entities is controversial among clinicians.

CM-I is the most prevalent of the CM entities. Diagnosis of CM-I is currently based on the radiographic observation of variable herniation ( 3 or $5 \mathrm{~mm}$ ) of one or both cerebellar tonsils, with the cutoff of $5 \mathrm{~mm}$ being the most common and conservative criterion applied. ${ }^{1-3,5,23,31,32,34,39}$ Traditionally, it has been postulated that tonsillar herniation $(\mathrm{TH})$ is produced as a consequence of a cranial constriction due to a hypoplastic PCF (classic CM-I), but $\mathrm{TH}$ can also be produced by different mechanisms. ${ }^{33} \mathrm{Al}-$ though a proportion of patients with CM-I do not develop symptoms related to the condition (i.e., it represents an incidental radiological finding), the most common symptoms reported by CM-I patients are suboccipital headaches, dizziness, and cervical pain, ${ }^{32}$ and often other conditions such as syringomyelia or hydrocephalus are also present $^{32,51}$ The extent of TH does not necessarily correlate with symptom severity ${ }^{24,36}$ or surgical outcome. ${ }^{38} \mathrm{Al}$ though there is an ongoing controversy about the optimum surgical technique to be used in the treatment of CM, the most commonly used technique is PCF decompression, a procedure that is performed to increase space for the cerebellum and relieve pressure on the spinal cord. ${ }^{11}$

Since the concepts of CM-0 and CM-1.5 are relatively new, reports and morphometric studies focused on patients with these conditions are scarce. These studies have indicated that individuals with CM-0 or CM-1.5 display an overcrowded PCF and symptoms similar to CM-I patients. However, since TH is generally absent in CM- $0^{21,22,41,47}$ and the position of the brainstem in CM-1.5 is between that seen in CM-I and that seen in CM-II, ${ }^{26,48}$ there is a debate over the relevance and even the existence of these newer categories. ${ }^{35}$

The radiographic measurement of $\mathrm{TH}$ may not be the best anatomical feature to use for $\mathrm{CM}$ diagnosis. The most restrictive criterion includes a wide variety of CM-I patients, while it excludes others displaying a similarly overcrowded PCF but limited TH. Often, these patients (with CM-O and CM-I with moderate $\mathrm{TH}$ ) are misdiagnosed and do not receive surgical treatment. ${ }^{36,43}$ Therefore, in recent years, a number of studies have been conducted to identify additional parameters that may improve the diagnosis. For example, Alperin et al. ${ }^{3}$ identified 4 measures that differentiated CM-I patients from a healthy cohort with a sensitivity of $97 \%$ and specificity of $100 \%$. In a previous work, ${ }^{51}$ we developed a probability predictor based on a logistic regression (LR) model that considers 7 PCF measures and demonstrated a sensitivity of $93 \%$ and a specificity of $92 \%$ in differentiating patients with classic CM-I from those with a normal PCF. While these results were strong, the measurement methodology applied re- quired volumetric postprocessing that might not be available in many clinics and was very time consuming, since it required the measurement of several morphometric traits. Other studies that focused on the comparison of morphometric measurements between CM-I patients with and without a syrinx found significant correlations between the degrees of $\mathrm{TH}$ and syrinx formation; ${ }^{20,46}$ furthermore, either the clivus slope or the PCF depth was observed to be significantly smaller in CM-I patients with a syrinx. ${ }^{42,55}$ However, these results have not yet been replicated.

Machine-learning classification techniques have been applied to improve diagnosis of several diseases, including glaucoma, mild cognitive impairment, and dementia, 6,17, 25,44 with results suggesting that these techniques might be better than currently available methods for classifying patients or healthy individuals. Classifiers usually employ a supervised learning approach, in which the program is fed with cases of known diagnosis. The aim of the present study was to apply these methods to identify morphometric structures, different from $\mathrm{TH}$, that allow the discernment of structural PCF alterations. A number of machinelearning classifiers were formulated using a range of MRI morphometric features (from 2 to 7 ) on a large training set of CM-I imaging studies. The obtained classifiers were further tested on independent patient cohorts comprising patients with classic CM-I, CM-I with moderate TH, CM1.5, and CM- 0 . We believe that a better characterization of the PCF in patients with classic CM-I may allow a better understanding of the pathophysiology of the osseous anomaly and guide future studies focused on identifying its etiology as well as the design of alternative treatments.

\section{Methods \\ Ethics Statement}

This investigation was conducted according to the principles expressed in the Declaration of Helsinki and was approved by the Ethics Committee of the Vall d'Hebron University Hospital. Because the patients were selected retrospectively and the MR images analyzed were completely deidentified, no informed consent was required for the study.

\section{Patients}

A total of 195 adult CM patients of Spanish descent with a reduced PCF were retrospectively selected for this study. These patients were previously diagnosed and treated by the 2 authors in charge of surgical treatment at the Division of Neurosurgery of Vall d'Hebron University Hospital in Barcelona (J.S. and M.A.P.). Clinical evaluation in all patients included direct anamnesis, physical examination, neurophysiological studies (somatosensory evoked potentials, brain auditory evoked potentials, and polysomnography), and cranial and spinal MRI studies. Patients with complex CM-I ${ }^{34}$ were not included in this study since mechanistically we do not consider a reduced PCF to be the sole cause of their TH. For this study, following the strictest and most conservative criterion, according to the degree of brainstem and tonsillar herniation, patients were classified as having classic CM-I $(n=141)$, classic CM-I with moderate TH $(n=23), C M-1.5(n=24)$, or CM-0 $(n=$ 

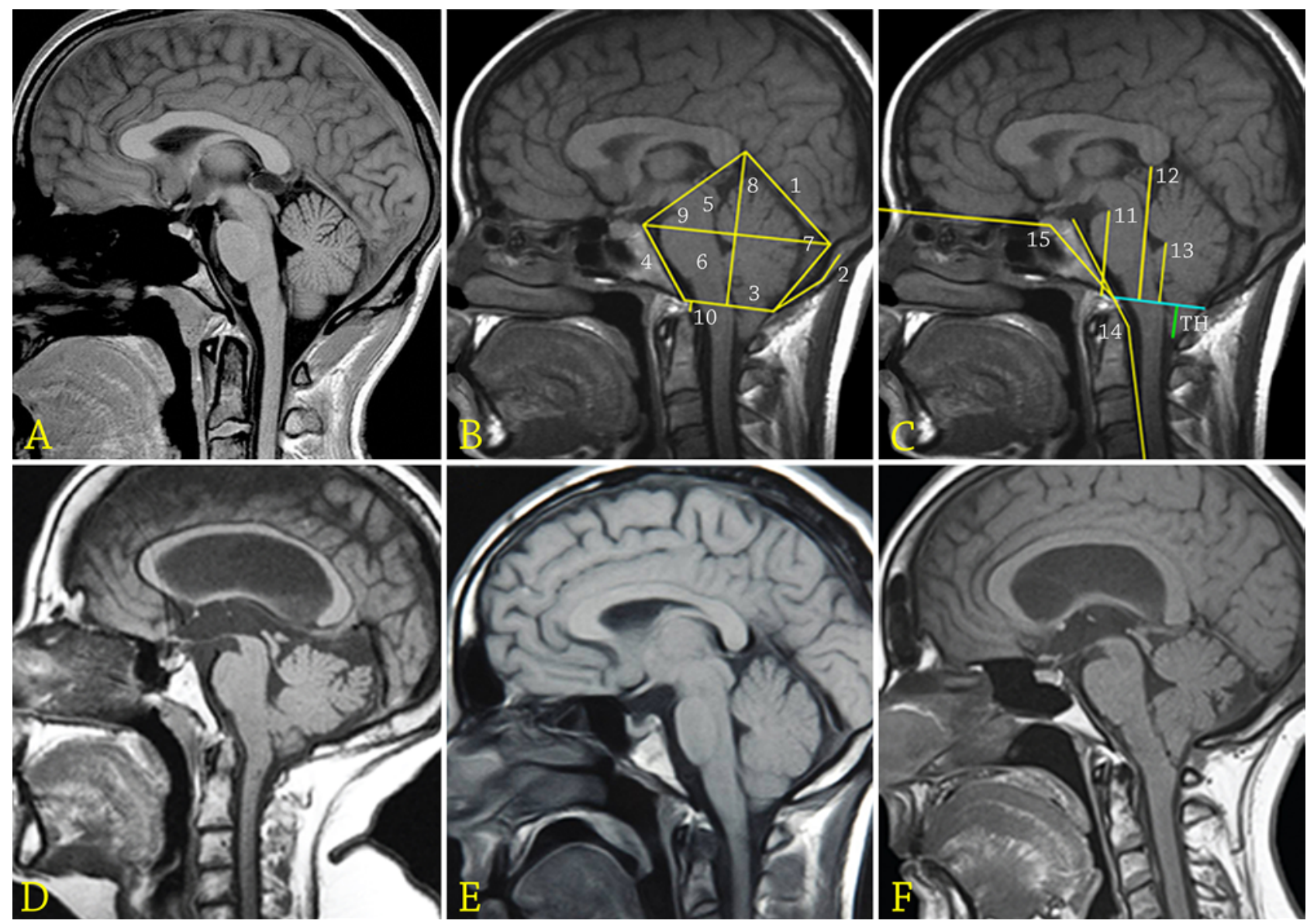

FIG. 1. Representative sagittal T1-weighted MR images corresponding to each of the analyzed cohorts: controls (A), CM-I (B and C), CM-0 (D), CM-I with moderate TH (E), and CM-1.5 (F). Numbers indicate the measurements performed in all individuals: 1 indicates tentorium length; 2, supraoccipital length; 3, anteroposterior diameter of FM; 4, clivus length; 5 , PCF area; 6, osseous PCF area; 7, tentorium angle; 8 , height PCF; 9 , width of PCF; 10, basilar impression; 11, distance from pons to FM; 12, distance from corpus callosum to FM; 13 , distance from fastigium to FM; 14 , Wackenheim angle; and 15, basal angle. Panels $B$ and $C$ are modified from Urbizu A, Poca MA, Vidal X, Rovira A, Sahuquillo J, Macaya A: MRI-based morphometric analysis of posterior cranial fossa in the diagnosis of Chiari malformation type I. J Neuroimaging 24:250-256, 2014. Used with permission. Figure is available in color online only.

7). Patients with CM-I and CM-1.5 displayed $\mathrm{TH} \geq 5 \mathrm{~mm}$ on midsagittal T1-weighted MR images (Fig. 1). Those patients with TH of 3-5 mm were considered to have CM-I with moderate $\mathrm{TH}$, and those with $\mathrm{TH}<3 \mathrm{~mm}$ were considered to have CM-0. The patients' clinical findings and related conditions are presented in Table 1.

As a control group, we included 50 individuals of Spanish descent ( 31 female, 19 male; mean age $35.6 \pm 7.6$ years) whose characteristics have previously been described. ${ }^{51}$

\section{PCF Morphometric Analysis}

In addition to the $\mathrm{TH}$ assessment described above, 15 specific linear, angular, and areal measures related to the PCF were also analyzed. These morphometric measurements were all performed by a single observer (A.U.). The specific measures analyzed were tentorium length, supraoccipital length (length of the squamous part of the occipital bone), anteroposterior diameter of the FM, clivus length, basilar impression, distance from the FM to the fastigium, distance from the FM to the cephalad aspect of the pons at the junction with the midbrain, distance from the FM to the most inferior aspect of the splenium of the corpus callosum, PCF area, osseous PCF area, width of the PCF, height of the PCF, basal angulation, Wackenheim angle, and tentorium angle (Fig. 1). These measurements were performed as described previously by Urbizu et al. ${ }^{51}$ High intraobserver reliability was demonstrated by calculating 2-way mixed intraclass correlation coefficients (with $95 \%$ confidence intervals) on repeated measures in 15 randomly selected cases.

MRI data were acquired using a 1.5-T scanner (Magnetom Symphony or Magnetom Vision, Siemens AG) equipped with a circular polarized receiver head array coil. In all CM patients and controls, sagittal, transverse, and coronal conventional T1-weighted spin-echo sequences were obtained (TR 450-600 msec, TE 12-20 msec, acquisitions 2). The sequences were obtained with 4- to $5-\mathrm{mm}$ section thickness and 0.1-0.3 interslice gap, with 144-256 $\times 256-384$ imaging matrix, and $196 \times 230-\mathrm{mm}$ FOV.

Brain MR images were analyzed using a picture ar- 
TABLE 1. Clinical and demographic characteristics of patients with $\mathrm{CM}-\mathrm{I}, \mathrm{CM}-\mathrm{I}$ with moderate $\mathrm{TH}, \mathrm{CM}-1.5$, and $\mathrm{CM}-0$

\begin{tabular}{|c|c|c|c|c|}
\hline Characteristic & CM-I Pts $(n=141)$ & CM-I Pts w/ Mod TH $(n=23)$ & CM-1.5 Pts $(n=24)$ & CM-0 Pts $(n=7)$ \\
\hline \multicolumn{5}{|l|}{ Sex (no.) } \\
\hline M & 44 & 6 & 2 & 3 \\
\hline $\mathrm{F}$ & 97 & 17 & 22 & 4 \\
\hline Mean age (yrs) & $42.0 \pm 13.0$ & $40.5 \pm 13.4$ & $44.0 \pm 11.8$ & $36.7 \pm 9.3$ \\
\hline Hydrocephalus & $32 / 127(25.2 \%)$ & $3 / 19(15.8 \%)$ & $5 / 24(20.8 \%)$ & $2 / 7(28.6 \%)$ \\
\hline Hydrosyringomyelia & $70 / 128(54.7 \%)$ & $5 / 19(26.3 \%)$ & $7 / 24(29.2 \%)$ & $3 / 7(42.9 \%)$ \\
\hline Kippel-Feil malformation & $2 / 125(1.6 \%)$ & $0 / 19(0 \%)$ & $0 / 24(0 \%)$ & $0 / 7(0 \%)$ \\
\hline Retrocurved odontoid & $14 / 120(11.7 \%)$ & $5 / 17(29.4 \%)$ & $5 / 24(20.8 \%)$ & $0 / 6(0 \%)$ \\
\hline \multicolumn{5}{|l|}{ Signs \& symptoms } \\
\hline Asymptomatic & $10 / 123(8.1 \%)$ & $1 / 18(5.6 \%)$ & $0 / 24(0 \%)$ & $1 / 6(16.7 \%)$ \\
\hline Mean age at manifestation (yrs) & $35.0 \pm 13.4$ & $32.1 \pm 10.4$ & $36.6 \pm 11.5$ & $27.8 \pm 7.5$ \\
\hline Mean time since onset (mos) & $71.8 \pm 77.3$ & $83.1 \pm 102.0$ & $92.6 \pm 91.0$ & $82.0 \pm 65.0$ \\
\hline Headaches & $83 / 122(68.0 \%)$ & $11 / 16(68.7 \%)$ & $19 / 24(79.2 \%)$ & $2 / 6(33.3 \%)$ \\
\hline Cough headache & $58 / 119(48.7 \%)$ & $6 / 19(31.6 \%)$ & $11 / 24(45.8 \%)$ & $1 / 6(16.7 \%)$ \\
\hline Neck pain & $46 / 123(37.4 \%)$ & $6 / 19(31.6 \%)$ & $6 / 24(25 \%)$ & $1 / 6(16.7 \%)$ \\
\hline Dizziness & $34 / 123(27.6 \%)$ & $4 / 19(21.0 \%)$ & $6 / 24(25 \%)$ & $0 / 6(0 \%)$ \\
\hline Vertigo & $7 / 123(5.7 \%)$ & $2 / 19(10.5 \%)$ & 4/23 (17.4\%) & $1 / 6(16.7 \%)$ \\
\hline Visual alterations & $11 / 123(8.9 \%)$ & $0 / 19(0 \%)$ & $0 / 24(0 \%)$ & $0 / 6(0 \%)$ \\
\hline Nystagmus & $16 / 81(19.7 \%)$ & $1 / 8(12.5 \%)$ & $2 / 15(13.3 \%)$ & $1 / 2(50 \%)$ \\
\hline Kyphoscoliosis & $17 / 82(20.7 \%)$ & $2 / 10(20 \%)$ & $1 / 16(6.2 \%)$ & $2 / 2(100 \%)$ \\
\hline Fatigue & $10 / 122(8.2 \%)$ & $3 / 19(15.8 \%)$ & $1 / 24(4.2 \%)$ & $1 / 6(16.7 \%)$ \\
\hline Instability & $23 / 122(18.8 \%)$ & $3 / 19(15.8 \%)$ & $7 / 24(29.2 \%)$ & $2 / 6(33.3 \%)$ \\
\hline Sensory loss & $32 / 122(26.2 \%)$ & $3 / 19(15.8 \%)$ & $2 / 24(8.3 \%)$ & $2 / 6(33.3 \%)$ \\
\hline Motor weakness & $27 / 123(21.5 \%)$ & $3 / 19(15.8 \%)$ & $4 / 24(16.7 \%)$ & $2 / 6(33.3 \%)$ \\
\hline Dysphagia & $18 / 123(14.6 \%)$ & $0 / 19(0 \%)$ & $5 / 24(20.8 \%)$ & $0 / 6(0 \%)$ \\
\hline Dysphonia & $6 / 123(4.9 \%)$ & $1 / 19(5.3 \%)$ & $5 / 24(20.8 \%)$ & $0 / 6(0 \%)$ \\
\hline Gait disturbances & $15 / 123(12.2 \%)$ & $2 / 19(10.5 \%)$ & $3 / 24(12.5 \%)$ & $1 / 6(16.7 \%)$ \\
\hline UE paresthesia & $56 / 123(45.5 \%)$ & $6 / 19(31.6 \%)$ & $9 / 24(37.5 \%)$ & $3 / 6(50 \%)$ \\
\hline LE paresthesia & $21 / 123(17.1 \%)$ & $0 / 19(0 \%)$ & $1 / 24(4.2 \%)$ & $1 / 6(16.7 \%)$ \\
\hline Anxiety & $22 / 121(18.2 \%)$ & $4 / 19(21 \%)$ & $4 / 24(16.7 \%)$ & $1 / 6(16.7 \%)$ \\
\hline Depression & $17 / 122(13.9 \%)$ & $1 / 18(5.6 \%)$ & $3 / 24(12.5 \%)$ & $1 / 6(16.7 \%)$ \\
\hline \multicolumn{5}{|l|}{ Therapeutic procedures } \\
\hline PCF decompression & $71 / 86(82.6 \%)$ & $6 / 9(66.7 \%)$ & $16 / 18(88.9 \%)$ & $2 / 4(50 \%)$ \\
\hline
\end{tabular}

$\mathrm{LE}=$ lower extremity; $\bmod =$ moderate; $\mathrm{pt}=$ patient; $\mathrm{UE}=$ upper extremity.

Sex composition is shown for each cohort. Means are presented \pm SD.

chiving and communication system (PACS) on a Numaris/4 Syngo postprocessing workstation, version MR 2004A (Siemens AG) and ImageJ (the Java image processing program), version 1.41 (http://rsb.info.nih.gov/ij).

\section{Data Analysis}

Statistical Analysis

Data are presented as percentages for categorical variables for the whole cohort of CM patients and as mean values with standard deviations for continuous variables in the cohorts of CM patients and controls. Comparative analyses were performed between sex- and age-matched CM-I patients $(\mathrm{n}=117)$ and controls and between CM-I patients with $(n=69)$ and without $(n=48)$ syringomyelia, applying parametric or nonparametric tests (ANOVA or Mann-Whitney U-test, respectively). Statistical significance, initially set at $\mathrm{p}<0.05$, was modified to $\mathrm{p}<$ 0.0033 after applying Bonferroni correction for multiple comparisons. Parametric (Pearson) and nonparametric (Spearman's rho) correlations were performed using CM-I patient $(n=117)$ and control data to identify correlations between the parameters considered most relevant by the supervised machine-learning classifiers and the clivus and supraoccipital lengths. Correlations of the basal and Wackenheim angles with distances from the FM to different neural structures were also investigated. All statistical analyses were performed using SPSS 17.0 (SPSS, Inc.).

\section{Supervised Machine-Learning Classifiers}

Supervised classification consists of identifying to 
which category a new data point belongs, based on either data structures or parametric mathematical models learned from training data. ${ }^{54}$ Each data point in the training set consists of a vector $(X, Y)$, where $x \in R^{n}$ is the feature vector whose components $x_{1}, \ldots, x_{n}$ are the feature variables (morphometric measurements in our case) and $Y$ is the label variable, taking value 1 or 0 ( 1 if it corresponds to a CM-I patient or 0 if it belongs to a control patient). In the present study, we considered feature vectors of different sizes $(2,3,4,5,6$, and 7$)$.

We applied the following 7 supervised classification methods:

Naïve Bayes (NB): This is a probabilistic classifier built upon the Bayes theorem and the assumption that the feature variables are conditionally independent given the class $Y$. The a posteriori distribution $P(Y \mid X)$ is computed by $P(Y) P\left(x_{1} \mid Y\right) \ldots P\left(x_{n} \mid Y\right)$. In particular, the gaussian NB classifier assumes a gaussian distribution for each feature variable, and their means and standard deviations are computed from the training data of each class. Then, the NB classifier assigns the most probable a posteriori class to a data point..$^{54}$

Decision Tree (DT): This is a nonparametric classification method based on a binary tree that is built in a top-down manner from the training data and then used to classify a new data point by sorting down the tree from the root node to any leaf node, testing the feature variable specified at each node?

k-Nearest Neighbors (k-NN): This is a nonparametric method that assigns a new data point to a category that is most frequently found among its $\mathrm{k}$ closest training points. A common distance used to obtain the k-NN is the Euclidean distance. In our experiments, we used $\mathrm{k}=3.15$

Logistic Regression (LR): This method produces a posterior probability $P(Y \mid X)$ for a data point $X$. For binary classification, the model assumes that it is a transformation of a linear combination of the feature variables, given by $P(Y=1 \mid X)=1 /\left[1+e^{-\left(b_{0}+b_{1} x_{1}+\ldots+b_{n} x_{n}\right)}\right]$, where $b_{0}, \ldots, b_{n}$ are the model parameters obtained from the training data by maximum likelihood. ${ }^{14}$

Linear and Quadratic Discriminant Analysis: These methods assume that the conditional probability $P(Y \mid X)$ is modeled by a multivariate gaussian distribution for each class, that is,

$P(X \mid Y)=\frac{1}{(2 \pi)^{n}\left|\sum_{Y}\right|^{1 / 2}} \exp \left(-\frac{1}{2}\left(X-\mu_{Y}\right)^{t} \sum_{Y}^{-1}\left(X-\mu_{Y}\right)\right)$,

where $\mu_{Y}$ and $\Sigma_{Y}$ are the mean vector and the covariance matrix corresponding to the class $Y$. Linear discriminant analysis assumes further that $\Sigma_{Y}$ is the same for all classes. The training data are used to estimate $\mu_{Y}$ and that $\Sigma_{Y}$. The discriminant analysis classifier assigns the class with smallest misclassification error. ${ }^{28}$

Support Vector Machine (SVM): This method finds a hyperplane that separates the data set by maximizing the distance between the different classes. This hyperplane is learned from the training data and used to classify the new data depending on which side of the hyperplane the new point is located on. ${ }^{53}$

To quantify the goodness of a classifier, we computed the following values over the test data: true positives (TPs), true negatives (TNs), false positives (FPs) and false negatives (FNs). Then, we defined accuracy as $(|\mathrm{TP}|+|\mathrm{TNI}|) /$ $(|\mathrm{TP}|+|\mathrm{TN}|+|\mathrm{FP}|+\mid \mathrm{FNI})$, sensitivity as $|\mathrm{TP}| /(|\mathrm{TP}|+\mid \mathrm{FNI})$, and specificity as $\mid \mathrm{TNI} /(|\mathrm{TN}|+\mid \mathrm{FPI})$. It was assumed that the $\mathrm{CM}$ group classification by the physician was perfect. In addition, we used a method called K-fold cross-validation. ${ }^{45}$ In this method, the data set was partitioned into $\mathrm{K}$ folds of approximately the same size: $\mathrm{K}-1$ folds were used for the learning process and the 1 fold left out was used as a test set. This process was repeated $\mathrm{K}$ times. The accuracy, specificity, and sensitivity of each classifier were estimated as the mean of the accuracies, specificities, and sensitivities of the $\mathrm{K}$ test sets. In our experiments, we fixed the value of $\mathrm{K}$ at 4 . The above algorithms were implemented using the Statistics and Machine Learning Toolbox (MathWorks, Inc.) with default parameters or as specified above.

\section{Results}

Table 2 shows the average values of TH and 15 PCF measurements performed in the whole classic CM-I patient cohort $(n=141)$, CM-I patients with syrinx $(n=69)$, CM-I patients without syrinx $(n=48), C M-I$ patients with moderate TH $(n=23), C M-1.5$ patients $(n=24), C M-0$ patients $(n=7)$, and controls $(n=50)$. Statistically significant differences $(\mathrm{p}<0.0033)$ were observed between the CM-I $(n=117)$ and the control cohorts in the following features: distance from corpus callosum, fastigium, and pons to FM; tentorium, clivus, and supraoccipital lengths; PCF and osseous PCF areas; height of PCF; and basal angle. Among CM-I patients, no significant differences were found between patients with and without syringomyelia for any of the 15 PCF measurements. Thus, both cohorts were considered together for the identification of important features in classic CM-I using supervised machinelearning classifiers.

After application of the 7 different classification methods with combinations of 2, 3, 4, 5, 6, and 7 features in the training MR images obtained in 117 patients with classic CM-I and 50 controls, we found that the best classifiers had a similar degree of specificity and sensitivity, ranging from $79 \%$ to $96 \%$ and $86 \%$ to $93 \%$, respectively (Table 3 ). However, the best classification (in terms of high accuracy with a reduced number of features) was obtained using the SVM method, combining 3 features. This classifier predicted with $90 \%$ specificity and sensitivity, indicating that the individuals presented characteristics compatible with classic CM-I when the value of the prediction given by the following formula was positive (with distances measured in millimeters).

\section{Prediction $=11.5785-0.2352 \times$ distance from \\ fastigium to $F M-0.2435 \times$ distance from pons to $F M$ $+0.0419 \times$ basal angle}

When only 2 features were used, the best classifier (kNN) showed a specificity of $86 \%$ and a sensitivity of $91 \%$; when 4 features were used, the best classifiers (k-NN, SVM, and NB) showed a specificity of $90 \%$ and a sensitivity of $88 \%$ (k-NN and SVM) or a specificity of $88 \%$ and a sensitivity of $90 \%$ (NB); when 5 features were used, the best classifier (k-NN) showed a specificity of $92 \%$ and a 
TABLE 2. Posterior cranial fossa and TH measurements in patients with CM-I, CM-I with moderate TH, CM-1.5, and CM-0

\begin{tabular}{|c|c|c|c|c|c|c|c|}
\hline Variable & $\begin{array}{l}\text { CM-I Pts } \\
(n=141)\end{array}$ & $\begin{array}{c}\text { CM-I Pts w/ } \\
\text { Syrinx }(n=69)\end{array}$ & $\begin{array}{l}\text { CM-I Pts w/o } \\
\text { Syrinx }(n=48)\end{array}$ & $\begin{array}{l}\text { CM-I Pts w/ Mod } \\
\text { TH }(n=23)\end{array}$ & $\begin{array}{c}\text { CM-1.5 Pts } \\
(n=24)\end{array}$ & $\begin{array}{l}\text { CM-0 Pts } \\
(n=7)\end{array}$ & $\begin{array}{l}\text { Controls } \\
(n=50)\end{array}$ \\
\hline \multicolumn{8}{|l|}{ Sex (no.) } \\
\hline M & 44 & 26 & 18 & 6 & 2 & 3 & 19 \\
\hline $\mathrm{F}$ & 97 & 43 & 30 & 17 & 22 & 4 & 31 \\
\hline $\mathrm{TH}$ & $10.7 \pm 5.1$ & $11.1 \pm 5.6$ & $10.2 \pm 4.4$ & $4.1 \pm 0.5$ & $12.8 \pm 4.3$ & $1.1 \pm 1.2$ & $-4.9 \pm 3.7$ \\
\hline Tentorium length & $50.6 \pm 5.0$ & $50.7 \pm 5.3$ & $50.5 \pm 4.6$ & $51.6 \pm 4.1$ & $49.5 \pm 6.4$ & $56.5 \pm 7.1$ & $53.1 \pm 4.8$ \\
\hline Supraoccipital length & $40.8 \pm 5.9$ & $41.3 \pm 5.7$ & $40.0 \pm 6.0$ & $44.0 \pm 8.0$ & $42.6 \pm 4.4$ & $45.1 \pm 9.9$ & $43.8 \pm 5.0$ \\
\hline AP diameter of FM & $35.0 \pm 3.1$ & $34.6 \pm 3.0$ & $35.4 \pm 3.3$ & $32.2 \pm 3.3$ & $32.8 \pm 2.8$ & $31.4 \pm 3.4$ & $35.4 \pm 3.0$ \\
\hline Clivus length & $42.0 \pm 3.9$ & $42.2 \pm 3.7$ & $41.9 \pm 4.2$ & $41.0 \pm 4.0$ & $40.9 \pm 4.1$ & $44.7 \pm 2.2$ & $47.0 \pm 3.3$ \\
\hline PCF area $\left(\mathrm{cm}^{2}\right)$ & $33.7 \pm 4.0$ & $33.9 \pm 4.2$ & $33.4 \pm 3.6$ & $32.9 \pm 3.3$ & $32.0 \pm 3.6$ & $36.2 \pm 4.2$ & $37.8 \pm 3.5$ \\
\hline Osseous PCF area $\left(\mathrm{cm}^{2}\right)$ & $20.0 \pm 2.9$ & $20.3 \pm 2.9$ & $19.7 \pm 2.8$ & $19.3 \pm 2.8$ & $19.5 \pm 2.7$ & $20.6 \pm 2.7$ & $23.7 \pm 2.8$ \\
\hline Distance corpus callosum to FM & $56.0 \pm 4.7$ & $55.9 \pm 4.6$ & $56.2 \pm 4.7$ & $55.5 \pm 4.1$ & $55.2 \pm 4.0$ & $60.7 \pm 5.1$ & $63.3 \pm 3.2$ \\
\hline PCF height & $62.6 \pm 6.2$ & $62.7 \pm 6.8$ & $62.5 \pm 5.4$ & $61.3 \pm 5.2$ & $61.0 \pm 6.4$ & $66.0 \pm 7.3$ & $68.5 \pm 4.9$ \\
\hline PCF width & $85.6 \pm 4.9$ & $85.8 \pm 4.9$ & $85.5 \pm 4.9$ & $86.1 \pm 3.2$ & $83.7 \pm 4.9$ & $89.3 \pm 6.8$ & $85.7 \pm 4.2$ \\
\hline Distance fastigium to FM & $25.8 \pm 4.2$ & $25.8 \pm 4.6$ & $25.9 \pm 3.8$ & $27.1 \pm 3.2$ & $25.0 \pm 3.3$ & $29.0 \pm 2.5$ & $31.6 \pm 2.2$ \\
\hline Distance pons to FM & $35.8 \pm 4.5$ & $35.8 \pm 4.7$ & $35.8 \pm 4.3$ & $35.9 \pm 5.0$ & $34.8 \pm 3.9$ & $40.3 \pm 5.3$ & $43.2 \pm 3.2$ \\
\hline Basal angle $\left({ }^{\circ}\right)$ & $133.1 \pm 6.9$ & $133.1 \pm 7.4$ & $133.1 \pm 6.3$ & $134.7 \pm 6.7$ & $135.0 \pm 7.4$ & $133.5 \pm 11.1$ & $127.8 \pm 4.2$ \\
\hline Tentorium angle $\left({ }^{\circ}\right)$ & $90.4 \pm 8.3$ & $89.9 \pm 9.1$ & $91.1 \pm 7.0$ & $84.0 \pm 8.1$ & $86.6 \pm 7.7$ & $86.2 \pm 12.0$ & $93.2 \pm 7.1$ \\
\hline Wackenheim angle $\left(^{\circ}\right)$ & $155.9 \pm 10.1$ & $155.7 \pm 10.6$ & $156.3 \pm 9.6$ & $152.4 \pm 9.9$ & $153.2 \pm 10.2$ & $155.7 \pm 10.5$ & $154.2 \pm 7.2$ \\
\hline Basilar impression & $-4.9 \pm 3.1$ & $-5.0 \pm 3.6$ & $-4.6 \pm 2.1$ & $-4.6 \pm 1.6$ & $-3.7 \pm 2.1$ & $-5.6 \pm 2.4$ & $-4.2 \pm 2.3$ \\
\hline
\end{tabular}

$\mathrm{AP}=$ anteroposterior

Sex composition is shown for each cohort. Mean values \pm SD are in millimeters unless otherwise indicated.

sensitivity of $90 \%$; and when 6 or 7 features were used, the best classifiers (LR when 6 features were used and SVM when 7 were used) showed a specificity of $90 \%$ and a sen- sitivity of $92 \%$. Table 3 shows the best feature combination for each condition with the specificity and sensitivity values obtained by the best 42 classifiers.

TABLE 3. Accuracies of 7 supervised classifiers using different numbers of features expressed in percentages of specificity and sensitivity considering a sex-matched CM-I control cohort

\begin{tabular}{|c|c|c|c|c|c|c|c|}
\hline $\begin{array}{l}\text { No. of } \\
\text { Features }\end{array}$ & $\begin{array}{l}\text { Linear Discriminant } \\
\text { Analysis }\end{array}$ & $\begin{array}{c}\text { Quadratic } \\
\text { Discriminant Analysis }\end{array}$ & $\begin{array}{l}\text { Naïve } \\
\text { Bayes }\end{array}$ & $\begin{array}{l}\text { Decision } \\
\text { Tree }\end{array}$ & $\begin{array}{l}\text { Logistic } \\
\text { Regression }\end{array}$ & $\begin{array}{l}\text { k-Nearest } \\
\text { Neighbors }\end{array}$ & $\begin{array}{l}\text { Support Vector } \\
\text { Machine }\end{array}$ \\
\hline \multicolumn{8}{|c|}{ Accuracy obtained by the best performance classifiers } \\
\hline 2 & $82 / 91$ & $82 / 91$ & $88 / 86$ & $79 / 91$ & $82 / 91$ & $86 / 91$ & $84 / 91$ \\
\hline 3 & $84 / 93$ & $84 / 92$ & $88 / 87$ & $82 / 90$ & $86 / 92$ & $90 / 88$ & $90 / 90$ \\
\hline 4 & $86 / 91$ & $86 / 92$ & $88 / 90$ & $82 / 87$ & $86 / 92$ & $90 / 88$ & $90 / 88$ \\
\hline 5 & $88 / 91$ & $88 / 91$ & $92 / 87$ & $84 / 91$ & $86 / 92$ & $92 / 90$ & $88 / 93$ \\
\hline 6 & $88 / 92$ & $86 / 95$ & $90 / 89$ & $84 / 91$ & $90 / 92$ & $92 / 88$ & $90 / 91$ \\
\hline 7 & $88 / 92$ & $88 / 93$ & $92 / 86$ & $84 / 90$ & $90 / 91$ & $96 / 85$ & $90 / 92$ \\
\hline \multicolumn{8}{|c|}{ Features used by the best performance classifiers* } \\
\hline 2 & 11,13 & 11,12 & 11,13 & 11,14 & 11,13 & 11,14 & 11,13 \\
\hline 3 & $11,14,15$ & $11,14,15$ & $10,11,13$ & $10,11,14$ & $11,14,15$ & $9,11,12$ & $11,13,15$ \\
\hline 4 & $11,13,14,15$ & $8,12,13,14$ & $8,11,14,15$ & $3,9,12,13$ & $3,11,14,15$ & $6,9,11,12$ & $6,9,12,15$ \\
\hline 5 & $4,11,12,14,15$ & $8,12,13,14,15$ & $2,3,10,12,13$ & $6,9,11,12,14$ & $5,11,12,13,14$ & $5,6,9,11,12$ & $8,11,12,13,14$ \\
\hline 6 & $8,11,12,13,14,15$ & $6,9,10,13,14,15$ & $3,6,11,12,13,15$ & $6,9,11,12,14,15$ & $4,5,11,12,13,14$ & $3,5,9,11,12,13$ & $8,11,12,13,14,15$ \\
\hline 7 & $2,6,8,11,2,13,14$ & $1,5,8,9,12,13,14$ & $2,5,7,11,12,13,15$ & $1,6,9,11,12,14,15$ & $5,6,11,12,13,14,15$ & $5,6,8,10,12,13,14$ & $5,6,11,12,13,14,15$ \\
\hline
\end{tabular}

The CM-I cohort included 117 individuals ( 44 male and 73 female), and the control cohort included 50 (19 male and 31 female).

* Features used by the best performance classifiers are numbered according to the measurements performed and presented in Fig. 1:1 $1=$ tentorium length; $2=$ supraoccipital length; $3=$ anteroposterior diameter of FM; $4=$ clivus length; $5=$ PCF area; $6=$ osseous PCF area; $7=$ tentorium angle; $8=$ height PCF; $9=$ width PCF; $10=$ basilar impression; 11 = distance from pons to FM; 12 = distance from corpus callosum to FM; 13 = distance from fastigium to FM; $14=$ Wackenheim angle; $15=$ basal angle . 

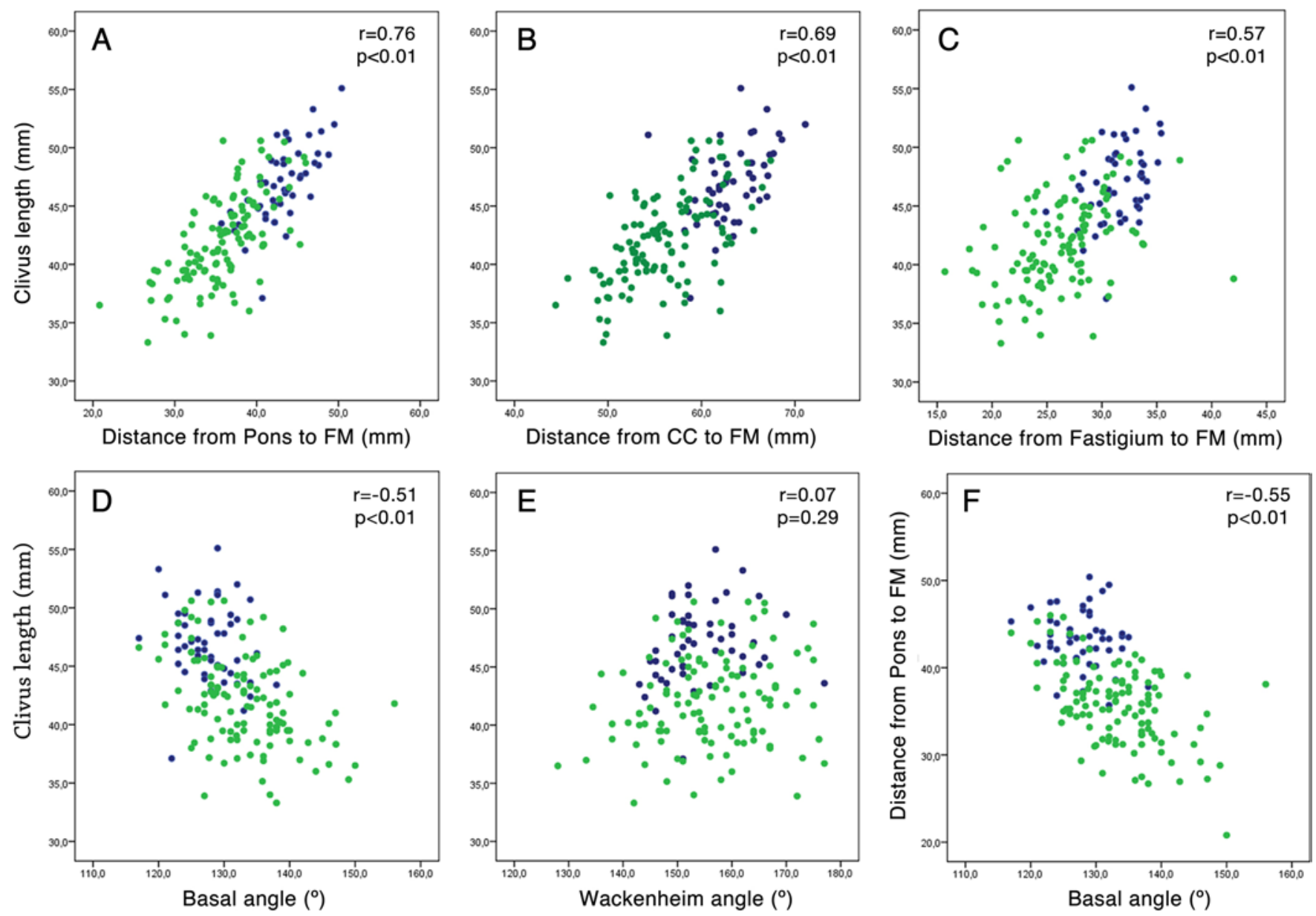

FIG. 2. Plots showing analyses of correlation between the clivus length and the 5 measurements most relevant according to the 7 supervised classification methods-the distance from the pons, the corpus callosum (CC), and the fastigium to the FM; the basal angle; and the Wackenheim angle (A-E, respectively) -and between the distance from the pons to the FM and the basal angle (F). Blue dots indicate measurements obtained in controls $(n=50)$, and green dots those obtained in patients with CM-I $(n=117)$. The respective correlation coefficients and $p$ values are shown for each analysis. Figure is available in color online only.

In terms of frequency, the most common features considered to obtain the best classifiers were the following: the distance from the pons to the FM (81\%), the Wackenheim angle (62\%), the distance from the corpus callosum to the FM (62\%), the distance from the fastigium to the FM (59\%), and the basal angle (45\%). The frequency of the remaining features was as follows: osseous PCF area (29\%), width of PCF (26\%), height of PCF (21\%), PCF area (21\%), basilar impression (12\%), anteroposterior diameter of FM (12\%), supraoccipital length (7\%), clivus length $(5 \%)$, tentorium length (5\%), and tentorium angle (2\%). All frequencies were calculated based on the percentage of occurrence of a particular feature within the total number of best combinations $(n=42)$.

Correlation analyses were performed between the most frequently considered parameters and the length of 2 osseous structures generally identified as altered in CM-I patients-the clivus and the squamous part of the occipital bone. Correlations involving the clivus length were in all cases stronger and more statistically significant than correlations involving the supraoccipital length. Regarding the clivus length, a strong correlation was observed with the distance from the pons to the FM $(r=0.76)$ and a moderate correlation with the distance from the corpus callosum to the FM and the distance from the fastigium to the FM $(r=0.69$ and $r=0.57$, respectively). There was a moderate negative correlation $(\mathrm{r}=-0.51)$ with the basal angle and no correlation with the Wackenheim angle $(r=0.07)$ (Fig. 2). Supraoccipital length showed a moderate correlation with the distance from the fastigium to the FM and the corpus callosum to the FM ( $r=0.36$ and $r=0.35$, respectively) and weak or no correlation with the basal angle, the distance from the pons to the FM, or the Wackenheim angle $(r=-0.23, r=0.194$, and $r=0.194$, respectively). Moderate negative correlations were also observed between the basal angle and the distance from the pons, corpus callosum, and fastigium to the FM $(r=-0.55, r=-0.48$, and $r=$ -0.46 , respectively) (Fig. 2). However, only weak correlations were observed between the Wackenheim angle and the distance from the pons and the corpus callosum to the $\mathrm{FM}(\mathrm{r}=0.27$ and $\mathrm{r}=0.16$, respectively).

When we applied the best combinations of features ob- 
TABLE 4. Accuracies of the 7 supervised classification methods using different numbers of features applied to independent cohorts of patients with $\mathrm{CM}-\mathrm{I}, \mathrm{CM}-\mathrm{I}$ patients with moderate $\mathrm{TH}, \mathrm{CM}-1.5$, and $\mathrm{CM}-0$

\begin{tabular}{|c|c|c|c|c|c|c|c|}
\hline $\begin{array}{l}\text { Cohort \& No. } \\
\text { of Features }\end{array}$ & $\begin{array}{l}\text { Linear Discriminant } \\
\text { Analysis }\end{array}$ & $\begin{array}{c}\text { Quadratic } \\
\text { Discriminant Analysis }\end{array}$ & $\begin{array}{l}\text { Naïve } \\
\text { Bayes }\end{array}$ & $\begin{array}{l}\text { Decision } \\
\text { Tree }\end{array}$ & $\begin{array}{c}\text { Logistic } \\
\text { Regression }\end{array}$ & $\begin{array}{l}\text { k-Nearest } \\
\text { Neighbors }\end{array}$ & $\begin{array}{c}\text { Support Vector } \\
\text { Machine }\end{array}$ \\
\hline \multicolumn{8}{|c|}{ CM-I pts ( $n=24 ;$ all F) } \\
\hline 2 & $96 \%$ & $93 \%$ & $96 \%$ & $93 \%$ & $96 \%$ & $98 \%$ & $96 \%$ \\
\hline 3 & $97 \%$ & $100 \%$ & $96 \%$ & $92 \%$ & $96 \%$ & $83 \%$ & $96 \%$ \\
\hline 4 & $96 \%$ & $97 \%$ & $93 \%$ & $88 \%$ & $96 \%$ & $85 \%$ & $88 \%$ \\
\hline 5 & $94 \%$ & $96 \%$ & $93 \%$ & $92 \%$ & $96 \%$ & $91 \%$ & $96 \%$ \\
\hline 6 & $96 \%$ & $92 \%$ & $96 \%$ & $92 \%$ & $96 \%$ & $94 \%$ & $96 \%$ \\
\hline 7 & $96 \%$ & $96 \%$ & $96 \%$ & $92 \%$ & $96 \%$ & $96 \%$ & $96 \%$ \\
\hline \multicolumn{8}{|c|}{ CM-I pts w/ mod TH (n = 23; 6 M, 17 F) } \\
\hline 2 & $96 \%$ & $92 \%$ & $96 \%$ & $86 \%$ & $96 \%$ & $76 \%$ & $96 \%$ \\
\hline 3 & $91 \%$ & $91 \%$ & $96 \%$ & $86 \%$ & $91 \%$ & $86 \%$ & $96 \%$ \\
\hline 4 & $93 \%$ & $90 \%$ & $96 \%$ & $90 \%$ & $91 \%$ & $90 \%$ & $87 \%$ \\
\hline 5 & $95 \%$ & $90 \%$ & $83 \%$ & $92 \%$ & $96 \%$ & $91 \%$ & $95 \%$ \\
\hline 6 & $96 \%$ & $91 \%$ & $90 \%$ & $92 \%$ & $96 \%$ & $91 \%$ & $95 \%$ \\
\hline 7 & $93 \%$ & $91 \%$ & $96 \%$ & $92 \%$ & $95 \%$ & $85 \%$ & $96 \%$ \\
\hline \multicolumn{8}{|c|}{ CM-1.5 pts ( $\mathrm{n}=24 ; 2 \mathrm{M}, 22 \mathrm{~F})$} \\
\hline 2 & $96 \%$ & $96 \%$ & $96 \%$ & $93 \%$ & $96 \%$ & $93 \%$ & $96 \%$ \\
\hline 3 & $96 \%$ & $96 \%$ & $96 \%$ & $93 \%$ & $96 \%$ & $86 \%$ & $96 \%$ \\
\hline 4 & $96 \%$ & $96 \%$ & $95 \%$ & $96 \%$ & $96 \%$ & $89 \%$ & $92 \%$ \\
\hline 5 & $94 \%$ & $96 \%$ & $93 \%$ & $92 \%$ & $96 \%$ & $91 \%$ & $96 \%$ \\
\hline 6 & $96 \%$ & $92 \%$ & $96 \%$ & $92 \%$ & $96 \%$ & $94 \%$ & $96 \%$ \\
\hline 7 & $96 \%$ & $96 \%$ & $96 \%$ & $92 \%$ & $96 \%$ & $86 \%$ & $96 \%$ \\
\hline \multicolumn{8}{|c|}{$\mathrm{CM}-0 \mathrm{pts}(\mathrm{n}=7 ; 3 \mathrm{M}, 4 \mathrm{~F})$} \\
\hline 2 & $68 \%$ & $57 \%$ & $71 \%$ & $61 \%$ & $57 \%$ & $50 \%$ & $68 \%$ \\
\hline 3 & $71 \%$ & $68 \%$ & $71 \%$ & $54 \%$ & $71 \%$ & $57 \%$ & $64 \%$ \\
\hline 4 & $68 \%$ & $71 \%$ & $50 \%$ & $68 \%$ & $71 \%$ & $57 \%$ & $68 \%$ \\
\hline 5 & $68 \%$ & $100 \%$ & $54 \%$ & $68 \%$ & $57 \%$ & $57 \%$ & $57 \%$ \\
\hline 6 & $64 \%$ & $82 \%$ & $71 \%$ & $68 \%$ & $57 \%$ & $57 \%$ & $64 \%$ \\
\hline 7 & $64 \%$ & $82 \%$ & $71 \%$ & $68 \%$ & $57 \%$ & $57 \%$ & $64 \%$ \\
\hline
\end{tabular}

tained by the 7 supervised machine-learning methods to independent cohorts with various $\mathrm{CM}$ entities, the accuracy obtained was 93\%-98\% for CM-I patients, $76 \%-96 \%$ for CM-I patients with moderate $\mathrm{TH}, 93 \%-96 \%$ for CM1.5 patients, and $50 \%-71 \%$ for CM- 0 patients when only 2 features were used. When 3 features were used, the accuracy was $83 \%-100 \%$ for CM-I patients, $86 \%-96 \%$ for CM-I patients with moderate $\mathrm{TH}, 86 \%-96 \%$ for $\mathrm{CM}-1.5$ patients, and $54 \%-71 \%$ for CM- 0 patients (Table 4). Figure 3 shows how the patients with different $\mathrm{CM}$ entities were classified by the SVM method using only 2 features (distance from the pons and the fastigium to the FM); $92.3 \%$ of the patients were well differentiated. Of the 6 patients who were predicted to be controls, 3 were actually $\mathrm{CM}-0$ patients.

\section{Discussion}

TH as a single measurement is not sufficient for radiographic diagnosis of all CM-I patients, and consequently, there is a need for novel and more accurate criteria. It is traditionally accepted that classic CM-I originates from a hypoplastic PCF; however, the structural features determining its reduction are still unclear. Therefore, a thorough characterization of the reduced PCF in patients with classic CM-I is essential to gain further insight into the origin of the alteration and to guide future studies directed both at understanding the etiology of different CM entities and at improving treatment for them. By means of a machine-learning approach applied to midsagittal MR image-based morphometric measurements, the present study aimed to 1) better characterize the PCF in a variety of patients with different $\mathrm{CM}$ entities by comparing their PCF features with those of a control cohort, 2) identify the main altered features, and 3) develop accurate and user-friendly classifiers, including combinations of 2 and 3 PCF features independent of the degree of $\mathrm{TH}$.

\section{Machine-Learning Approach for the Improvement of CM-I Diagnosis}

The identification of morphometric indicators for the diagnosis of CM-I as an alternative to TH has already been attempted. ${ }^{3,20,42,51,55}$ The novelty of the present study 

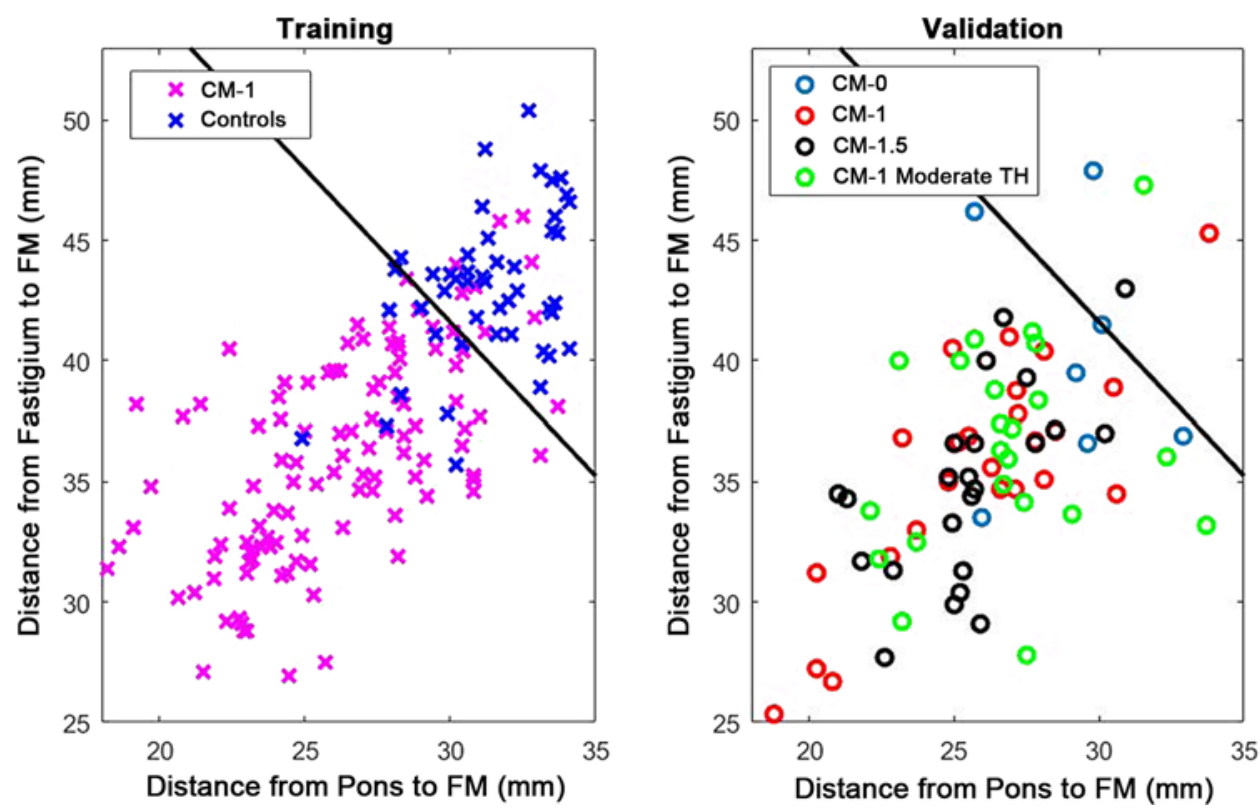

FIG. 3. Ordination plots depicting the distribution of data points used for training (left) and validation (right). The classification line generated by the support vector machine using only 2 features is also shown. Figure is available in color online only.

was in the use of a larger classic CM-I patient cohort and the application of 7 different supervised machine-learning methods. These methods "learned" automatically from data obtained in diagnosed CM-I cases and predicted whether a new undiagnosed patient belonged either to the classic CM-I group or the control group. Since possible structural differences have been suggested between CM-I patients with and without syringomyelia, ${ }^{42,55}$ a comparative morphometric analysis was performed to evaluate the homogeneity of our cohort of classic CM-I patients. In contrast to the previous studies (carried out in pediatric CM-I cases and including a smaller subject cohort), our analysis showed no statistically significant difference between the 2 subgroups for any of the 15 PCF measurements (Table 2 ), leading us to consider these subjects as a single cohort.

As expected, the specificity and sensitivity obtained with almost all of the classifiers improved as the number of features considered increased, but our objective was to obtain an accurate classifier based on the minimum number of features. Although the specificity and sensitivity values were slightly reduced compared with those in our previous work, ${ }^{51}$ it is remarkable that all of the classification methods investigated, except DT, provided high rates of accuracy (more than 87\%) using combinations of only 3 features, and 3 of these methods (NB, k-NN, and SVM) using combinations of only 2 features (Table 3 ). The high accuracy rates observed for these classifiers when applied to an independent classic CM-I cohort (Table 4) confirms the suitability of using only 2 or 3 features on midsagittal MR images independently of TH to discern classic CM-I.

The best classifier in this study used the distance from the pons and the fastigium to the FM and the basal angle. Indeed, the distance from the pons to the FM was also used by all of the classifiers with relatively high accuracy, indicating the importance of this feature for the morpho- metric detection of CM-I. The distance from the fastigium and the corpus callosum to the FM, the Wackenheim angle, and the basal angle were also frequently included. Surprisingly, the measurements that involved the parts of the occipital bone (clivus and supraocciput), features that were found to be distinctly shorter in our cohort and also in many other studies, $4,12,32,37,39,51$ were the third and fourth least useful classification features of all 15 (Table 3).

\section{Importance of the Basion for the PCF in Classic CM-I Patients}

It is noteworthy that the 5 features most frequently used by our most successful classifiers were all related to the clivus. Both the Wackenheim angle and the basal angle take into account the slope of the clivus, and the distances to the pons, fastigium, and corpus callosum are measured from the McRae line. This line is a landmark defined by the anterior and posterior margin of the FM, the basion and the opisthion, which are given by the basilar and supraoccipital parts of the occipital bone, respectively. In our CM-I cohort, the reduction of the occipital bone was more significant in the basilar part $(41.6 \pm 3.8 \mathrm{~mm}$ vs $47.0 \pm 3.3$ $\left.\mathrm{mm}, \mathrm{p}=3.4 \times 10^{13}\right)$ than in the supraoccipital part $(40.3 \pm$ $5.9 \mathrm{~mm}$ vs $43.8 \pm 5.0 \mathrm{~mm}, \mathrm{p}=0.002)$. These observations, together with the strong correlations of clivus length with the distances from the FM to the neural structures, and the fact that the degree of correlation of these distances increases with their proximity to the clivus, clearly suggest that the primary alteration in the CM-I PCF originates from the basion rather than the opisthion.

A change in the length and slope of the basilar part of the occipital bone can be translated into an abnormally elevated basion position. This elevated basion position in turn tilts the FM upward, resulting in a reduction in distances to neural structures and in a shallower and smaller 
PCF and osseous PCF areas. The strong and moderate correlations observed between the length of the clivus and the 5 discriminant features confirm the relevance of its shortening in CM-I patients. The shorter the clivus is, the higher the basion position is and the greater the reduction in clivus slope.

An elevated basion could in principle translate into a larger distance from the FM to the dens. According to our results, however, the distance to the dens was not altered, since the mean values obtained for the basilar impression in CM-I patients $(-4.4 \pm 3.1 \mathrm{~mm})$ and controls $(-4.2 \pm 2.3$ $\mathrm{mm})$ were not significantly different. It can be then postulated that the dens may also be elevated in CM-I. It was recently proposed that the basion and the dens could develop jointly in the embryo (sclerotome resegmentation), ${ }^{40}$ supporting the idea that an alteration of the basion position could result in a concomitant modification of the dens position, leading to additional craniocervical alterations in these patients. Additional measurements involving the odontoid process should be performed to confirm this hypothesis.

\section{Etiology of Classic CM-I}

Several theories have been proposed for the etiology of classic CM-I patients. ${ }^{8}$ The most accepted is based on an insufficiency of the paraxial mesoderm, which leads to a shorter basichondrocranium. This theory was proposed by Marin-Padilla and Marin-Padilla, who demonstrated with experimental studies in pregnant hamsters that a single dose of vitamin A administered on the 8th day of gestation could induce $\mathrm{CM} .{ }^{29}$ However, the specific mechanism by which vitamin A could affect the paraxial mesoderm, somites, or occipital bone has not been described. Our results support the notion that clivus length is related to basion position, clivus slope, and the position of the dens. It is unclear whether the clivus alterations (length and slope) produce the change in basion position or the basion position restricts the growth of the clivus (or basiocciput), changing its slope. The moderate correlation observed between some neural structure distances and the basal angle (Fig. 2) demonstrates that the position of the basion is determined not only by the length of the clivus but also by its slope. This is in agreement with a previous study in which 2 genetic variants (rs2899611 and rs6493979) located in the ALDH1A2 gene (whose product catalyzes the synthesis of retinoic acid, a metabolite of vitamin A) were not only found to be associated with classic CM-I but also correlated with the Wackenheim and basal angles and not with clivus length. ${ }^{52}$ This suggests that retinoic acid may be more critical in determining the slope than the length of the bone.

On the other hand, it has been reported that during the fetal period, the posterior basicranium undergoes retroflexion, moving the basion upward and dorsally, and decreasing the ventral depth of the PCF. An alteration of this accommodation of the basion position during development would also support our finding. An incorrect position of the basion during fetal life could hinder the normal growth of the basilar part of the occipital bone that is active until around the 2nd decade of life, when the spheno-occipital synchondrosis closes. ${ }^{27}$ Why this retroflexion happens is still unknown, but 2 hypotheses have been proposed: 1) to enlarge the intracranial space, or 2) as a consequence of the development of the upper airway. ${ }^{49}$ This second option would be in agreement with symptoms manifested by some CM-I patients, ${ }^{18}$ related to impaired oropharyngeal function. In fact, some recent studies have shown alterations in the oropharynx and airway of adult CM-I patients. ${ }^{19,50}$

\section{Characterization of PCF in Other CMs}

Clinical findings in the different cohorts of CM patients (classic CM-I with moderate TH, CM-1.5, and CM-0) were similar to those typically present in the patients with classic CM-I diagnosed according to the most conservative criterion $\left(\mathrm{TH}>5 \mathrm{~mm}\right.$ ) (Table 1). ${ }^{26,34,47,48}$ Although a statistical analysis of the morphometric parameters of these 3 different $\mathrm{CM}$ entities has not been performed (the cohort sizes were small and the cohorts could not be matched by sex), the morphometric data from these groups resembled more closely those from patients with classic CM-I than those from controls (Table 2). The high rate of accuracy obtained by applying the best classifiers to these cohorts (Table 4) suggests that patients with CM-I with moderate TH and those with CM-1.5 display a PCF structure similar to that of patients with classic CM-I (an elevated basion and a short and flattened clivus) and can be diagnosed and treated as a single entity. These results also confirm that the TH threshold of $5 \mathrm{~mm}$ is too restrictive for the correct diagnosis of all cases of CM.

When applied to the CM- 0 cohort, the obtained classifiers were not as accurate, mainly failing in prediction for 2 patients (29\%) who were misclassified as controls (Table 4). CM-0 patients have been described as having a reduced PCF similar to that of individuals with CM-I, ${ }^{41}$ and common underlying developmental mechanisms have been suggested for both entities. ${ }^{30}$ However, although the size of our cohort of patients with CM-0 was small and the standard deviation of their values was relatively large, the cohort analyzed in this study showed a PCF structure distinct from that seen in CM-I. Despite the fact that the PCF area measurements and clivus length were reduced in comparison with the control population, the tentorium, supraoccipital, and clivus lengths were larger than in patients with classic CM-I; also, normal distances from the different neural structures to the FM were observed along with greater PCF width than in controls (Table 2).

\section{Impact}

These results indicate that $\mathrm{TH}$, or at least the cutoff of $5 \mathrm{~mm}$, should not be used as a single radiological criterion for CM-I diagnosis. Using a combination of 2 or 3 morphometric features, all related to basion position, may improve the diagnosis of CM-I by including patients without prominent $\mathrm{TH}$ and facilitating decision making about possible surgical treatment in these cases.

Controversy continues regarding the optimal surgical technique to address classic CM. Successful surgical treatment requires appropriate patient selection and identification of the optimal procedure for the individual patient. PCF decompression with or without dura reconstruction is the most common procedure performed in these pa- 
tients, improving the clinical symptoms in most (around 80\%-90\%) CM-I, ${ }^{11,49}$ CM-0, ${ }^{21,22}$ and CM-1.5 cases, ${ }^{48}$ but additional procedures are often needed, ${ }^{16,56}$ and some complications can occur (9\%-42\% of cases). ${ }^{11,49}$ Furthermore, some patients do not report any significant improvement. ${ }^{13}$

These surgical approaches most directly alter the posterior anatomy. However, our findings indicate that the basioccipital hypoplasia present in classic CM-I occurs anteriorly. Thus, the standard surgical treatment does not directly affect the underlying defect but is rather a pragmatic and lower-risk method of opening space anteriorly. Surgical effectiveness may then be best assessed by measuring anterior alterations to the CSF space and/or tissues.

\section{Limitations}

One limitation of this study is that despite the fact that the CM-I and control cohorts used for the training were matched with respect to sex distribution, there were still more women than men in both cohorts, leading to a certain bias in the analysis. Dimensions are usually smaller in females than males, and results obtained from our analysis will better match and describe female CM patients than male CM patients. A second limitation of this study is the reduced number of controls $(n=50)$ in comparison with the number of CM-I patients $(n=117)$. Nevertheless, this study included a greater number of controls than most of the previous studies of CM-I and any study of CM0 . The fact that $\mathrm{TH}$ was measured using the midsagittal MR images could also be considered a limitation. Some $\mathrm{CM}$ patients have unequal herniation of the left and right cerebellar tonsils or have relatively normal midsagittal anatomy with abnormal parasagittal anatomy. Our study focused on morphometric measurements based on midsagittal MRI using software that is typically available in a clinic and assessments that could be conducted in a relatively short time frame. Other more advanced 3D morphometric techniques such as voxel-based morphometry, 3D atlas-based segmentation, and postprocessing tools were not considered, as these methods are often not available to clinicians. It should also be noted that the accuracy of the computation assumed that the clinical diagnosis was perfect, but unknown underlying comorbidities or related disorders might have remained undetected. Lastly, classic CM-I appears to be a rather heterogeneous disorder. Our study included subjects from a Spanish cohort, and it is unclear if the findings are specific to this population. Other morphometric studies performed in patients with classic CM-I showed a more prominent reduction of the supraoccipital length compared with the clivus, ${ }^{12,37}$ suggesting the existence of other types of reduced PCF. Also, we cannot rule out that, even in cohorts of patients with a similar PCF structure, the formula presented here might require minor adjustments of the coefficients for optimal fit and accuracy.

\section{Conclusions}

After analyzing images from a large cohort of patients with classic CM-I using different machine-learning classification methods, we obtained combinations of 2-7 PCF measurements, independent of $\mathrm{TH}$, that accurately predicted CM-I. Five parameters (distances from the fastigium, pons, and the corpus callosum to the FM, and the basal and Wackenheim angles) were more frequently used by the best 42 classifiers, and these parameters share a common landmark: the basion position. Alteration in the position of the basion was found to be common to the different CM entities, indicating that the current criterion based only on $\mathrm{TH}$ needs to be revised or, at least, the threshold be reduced to $3 \mathrm{~mm}$. We also provide a mathematical model based on only 3 parameters that predicts with $90 \%$ accuracy patients of different $\mathrm{CM}$ entities with classic PCF. Considering the major alteration of the basioccipital bone, success of surgical treatments in these patients could be assessed by measuring anterior alterations to the CSF space and/or tissues.

\section{Acknowledgments}

The authors report that this work was supported by Conquer Chiari (US) and that Dr. Urbizu is the recipient of a postdoctoral fellowship from Fundación Ramón Areces (Spain).

\section{References}

1. Aboulezz AO, Sartor K, Geyer CA, Gado MH: Position of cerebellar tonsils in the normal population and in patients with Chiari malformation: a quantitative approach with MR imaging. J Comput Assist Tomogr 9:1033-1036, 1985

2. Aitken LA, Lindan CE, Sidney S, Gupta N, Barkovich AJ, Sorel M, et al: Chiari type I malformation in a pediatric population. Pediatr Neurol 40:449-454, 2009

3. Alperin N, Loftus JR, Oliu CJ, Bagci A, Lee SH, Ertl-Wagner $\mathrm{B}$, et al: Magnetic resonance imaging measures of posterior cranial fossa morphology and cerebrospinal fluid physiology in Chiari malformation type I. Neurosurgery 75:515-522, 2014

4. Aydin S, Hanimoglu H, Tanriverdi T, Yentur E, Kaynar MY: Chiari type I malformations in adults: a morphometric analysis of the posterior cranial fossa. Surg Neurol 64:237241, 2005

5. Barkovich AJ, Wippold FJ, Sherman JL, Citrin CM: Significance of cerebellar tonsillar position on MR. AJNR Am J Neuroradiol 7:795-799, 1986

6. Bizios D, Heijl A, Hougaard JL, Bengtsson B: Machine learning classifiers for glaucoma diagnosis based on classification of retinal nerve fibre layer thickness parameters measured by Stratus OCT. Acta Ophthalmol 88:44-52, 2010

7. Breiman L, Friedman JH, Olshen RA, Stone CJ: Classification and Regression Trees. Boca Raton, FL: Chapman \& Hall, 1984

8. Cesmebasi A, Loukas M, Hogan E, Kralovic S, Tubbs RS, Cohen-Gadol AA: The Chiari malformations: a review with emphasis on anatomical traits. Clin Anat 28:184-194, 2015

9. Chiari $\mathrm{H}$ : Concerning alterations in the cerebellum resulting from cerebral hydrocephalus. 1891. Pediatr Neurosci 13:38,1987

10. Chiari H: Über Veränderungen des Kleinhirns, des Pons und der Medulla Oblongata infolge von congenitaler Hydrocephalie des Grosshirns. Denkschr der Kais Akad Wiss Wien math Naturw 63:71-116, 1895

11. Chotai S, Medhkour A: Surgical outcomes after posterior fossa decompression with and without duraplasty in Chiari malformation-I. Clin Neurol Neurosurg 125:182-188, 2014

12. Dagtekin A, Avci E, Kara E, Uzmansel D, Dagtekin O, Koseoglu A, et al: Posterior cranial fossa morphometry in symptomatic adult Chiari I malformation patients: comparative clinical and anatomical study. Clin Neurol Neurosurg 113:399-403, 2011

13. Deng X, Yang C, Gan J, Yang B, Wu L, Yang T, et al: 
Chiari malformation type 1.5 in male monozygotic twins: case report and literature review. Clin Neurol Neurosurg 130:155-158, 2015

14. Dobson AJ, Barnett A: An Introduction to Generalized Linear Models, ed 3. Boca Raton, FL: CRC Press, 2008

15. Fix E, Hodges JL Jr: Discriminatory Analysis. Nonparametric Discrimination: Consistency Properties. Randolph Field, TX: USAF School of Aviation Medicine, 1951

16. Förander P, Sjåvik K, Solheim O, Riphagen I, Gulati $\mathrm{S}$, Salvesen $\varnothing$, et al: The case for duraplasty in adults undergoing posterior fossa decompression for Chiari I malformation: a systematic review and meta-analysis of observational studies. Clin Neurol Neurosurg 125:58-64, 2014

17. Garrard P, Rentoumi V, Gesierich B, Miller B, GornoTempini ML: Machine learning approaches to diagnosis and laterality effects in semantic dementia discourse. Cortex 55:122-129, 2014

18. Greenlee JD, Donovan KA, Hasan DM, Menezes AH: Chiari I malformation in the very young child: the spectrum of presentations and experience in 31 children under age 6 years. Pediatrics 110:1212-1219, 2002

19. Guerreiro RB, Bittencourt L, Reis RC, Rotta JM, Tufik S, Botelho RV: Upper airway dimensions in patients with craniocervical junction malformations with and without sleep apnea. A pilot case-control study. Arq Neuropsiquiatr 73:336-341, 2015

20. Halvorson KG, Kellogg RT, Keachie KN, Grant GA, Muh CR, Waldau B: Morphometric Analysis of Predictors of Cervical Syrinx Formation in the Setting of Chiari I Malformation. Pediatr Neurosurg 51:137-141, 2016

21. Isik N, Elmaci I, Kaksi M, Gokben B, Isik N, Celik M: A new entity: Chiari Zero malformation and its surgical method. Turk Neurosurg 21:264-268, 2011

22. Iskandar BJ, Hedlund GL, Grabb PA, Oakes WJ: The resolution of syringohydromyelia without hindbrain herniation after posterior fossa decompression. J Neurosurg 89:212-216, 1998

23. Karagöz F, Izgi N, Kapíjcíjoğlu Sencer S: Morphometric measurements of the cranium in patients with Chiari type I malformation and comparison with the normal population. Acta Neurochir (Wien) 144:165-171, 2002

24. Khan AA, Bhatti SN, Khan G, Ahmed E, Aurangzeb A, Ali A, et al: Clinical and radiological findings in Arnold Chiari malformation. J Ayub Med Coll Abbottabad 22:75-78, 2010

25. Khazaee A, Ebrahimzadeh A, Babajani-Feremi A: Application of advanced machine learning methods on resting-state fMRI network for identification of mild cognitive impairment and Alzheimer's disease. Brain Imaging Behav 10:799-817, 2016

26. Kim IK, Wang KC, Kim IO, Cho BK: Chiari 1.5 malformation: an advanced form of Chiari I malformation. $\mathbf{J}$ Korean Neurosurg Soc 48:375-379, 2010

27. Krishan K, Kanchan T: Evaluation of spheno-occipital synchondrosis: A review of literature and considerations from forensic anthropologic point of view. J Forensic Dent Sci 5:72-76, 2013

28. Manning CD, Raghavan P, Schutze H: Introduction to Information Retrieval. Cambridge: Cambridge University Press, 2008, Vol 1

29. Marin-Padilla M, Marin-Padilla TM: Morphogenesis of experimentally induced Arnold-Chiari malformation. J Neurol Sci 50:29-55, 1981

30. Markunas CA, Tubbs RS, Moftakhar R, Ashley-Koch AE, Gregory SG, Oakes WJ, et al: Clinical, radiological, and genetic similarities between patients with Chiari Type I and Type 0 malformations. J Neurosurg Pediatr 9:372-378, 2012
31. Meadows J, Kraut M, Guarnieri M, Haroun RI, Carson BS: Asymptomatic Chiari Type I malformations identified on magnetic resonance imaging. J Neurosurg 92:920-926, 2000

32. Milhorat TH, Chou MW, Trinidad EM, Kula RW, Mandell $\mathrm{M}$, Wolpert C, et al: Chiari I malformation redefined: clinical and radiographic findings for 364 symptomatic patients. Neurosurgery 44:1005-1017, 1999

33. Milhorat TH, Nishikawa M, Kula RW, Dlugacz YD: Mechanisms of cerebellar tonsil herniation in patients with Chiari malformations as guide to clinical management. Acta Neurochir (Wien) 152:1117-1127, 2010

34. Moncho D, Poca MA, Minoves T, Ferré A, Cañas V, Sahuquillo J: Are evoked potentials clinically useful in the study of patients with Chiari malformation Type 1? J Neurosurg 126:606-619, 2017

35. Mottolese C, Szathmari A, Simon E, Rousselle C, RicciFranchi AC, Hermier M: Treatment of Chiari type I malformation in children: the experience of Lyon. Neurol Sci 32 (Suppl 3):S325-S330, 2011

36. Mueller DM, Oro' JJ: Prospective analysis of presenting symptoms among 265 patients with radiographic evidence of Chiari malformation type I with or without syringomyelia. J Am Acad Nurse Pract 16:134-138, 2004

37. Nishikawa M, Sakamoto H, Hakuba A, Nakanishi N, Inoue Y: Pathogenesis of Chiari malformation: a morphometric study of the posterior cranial fossa. J Neurosurg 86:40-47, 1997

38. Noudel R, Gomis P, Sotoares G, Bazin A, Pierot L, Pruvo JP, et al: Posterior fossa volume increase after surgery for Chiari malformation Type I: a quantitative assessment using magnetic resonance imaging and correlations with the treatment response. J Neurosurg 115:647-658, 2011

39. Noudel R, Jovenin N, Eap C, Scherpereel B, Pierot L, Rousseaux P: Incidence of basioccipital hypoplasia in Chiari malformation type I: comparative morphometric study of the posterior cranial fossa. Clinical article. J Neurosurg 111:1046-1052, 2009

40. Pang D, Thompson DN: Embryology and bony malformations of the craniovertebral junction. Childs Nerv Syst 27:523-564, 2011

41. Sekula RF Jr, Jannetta PJ, Casey KF, Marchan EM, Sekula LK, McCrady CS: Dimensions of the posterior fossa in patients symptomatic for Chiari I malformation but without cerebellar tonsillar descent. Cerebrospinal Fluid Res 2:11, 2005

42. Sgouros S, Kountouri M, Natarajan K: Posterior fossa volume in children with Chiari malformation Type I. J Neurosurg 105 (2 Suppl):101-106, 2006

43. Shehu BB, Ismail NJ, Mahmud MR, Hassan I: Chiari I malformation: a missed diagnosis. Ann Afr Med 5:206-208, 2006

44. Silva FR, Vidotti VG, Cremasco F, Dias M, Gomi ES, Costa VP: Sensitivity and specificity of machine learning classifiers for glaucoma diagnosis using spectral domain OCT and standard automated perimetry. Arq Bras Oftalmol 76:170174, 2013

45. Stone M: Cross-validatory choice and assessment of statistical predictions. J R Stat Soc B 36:111-147, 1974

46. Strahle J, Muraszko KM, Kapurch J, Bapuraj JR, Garton $\mathrm{HJ}$, Maher CO: Chiari malformation Type I and syrinx in children undergoing magnetic resonance imaging. $\mathbf{J}$ Neurosurg Pediatr 8:205-213, 2011

47. Tubbs RS, Elton S, Grabb P, Dockery SE, Bartolucci AA, Oakes WJ: Analysis of the posterior fossa in children with the Chiari 0 malformation. Neurosurgery 48:1050-1055, 2001

48. Tubbs RS, Iskandar BJ, Bartolucci AA, Oakes WJ: A critical analysis of the Chiari 1.5 malformation. J Neurosurg 101 (2 Suppl):179-183, 2004 
49. Tubbs RS, Oakes WJ (eds): The Chiari Malformations. New York: Springer, 2013

50. Urbizu A, Ferre A, Poca MA, Rovira A, Sahuquillo J, Martin BA, et al: Cephalometric oropharynx and oral cavity analysis in Chiari malformation Type I: a retrospective case-control study. J Neurosurg 126:626-633, 2016

51. Urbizu A, Poca MA, Vidal X, Rovira A, Sahuquillo J, Macaya A: MRI-based morphometric analysis of posterior cranial fossa in the diagnosis of Chiari malformation type I. J Neuroimaging 24:250-256, 2014

52. Urbizu A, Toma C, Poca MA, Sahuquillo J, Cuenca-León E, Cormand B, et al: Chiari malformation type I: a case-control association study of 58 developmental genes. PLoS One 8:e57241, 2013

53. Vapnik VN: The Nature of Statistical Learning Theory. New York: Springer, 2013

54. Witten IH, Frank E, Hall M: Data Mining: Practical Machine Learning Tools and Techniques, ed 3. Burlington, MA: Morgan Kaufmann Publishers, 2011

55. Yan H, Han X, Jin M, Liu Z, Xie D, Sha S, et al: Morphometric features of posterior cranial fossa are different between Chiari I malformation with and without syringomyelia. Eur Spine J 25:2202-2209, 2016

56. Zhao JL, Li MH, Wang CL, Meng W: A systematic review of Chiari I malformation: techniques and outcomes. World Neurosurg 88:7-14, 2016

\section{Disclosures}

The authors report no conflict of interest concerning the materials or methods used in this study or the findings specified in this paper.

\section{Author Contributions}

Conception and design: Urbizu, Martin, Español. Acquisition of data: Urbizu, Moncho, Rovira, Poca, Sahuquillo, Macaya. Analysis and interpretation of data: Urbizu, Español. Drafting the article: Urbizu, Martin, Español. Critically revising the article: all authors. Reviewed submitted version of manuscript: all authors. Approved the final version of the manuscript on behalf of all authors: Urbizu. Statistical analysis: Español.

\section{Correspondence}

Aintzane Urbizu, Duke Molecular Physiology Institute, Duke University School of Medicine, 300 N Duke St., Durham, NC 27701. email: aintzane.urbizu.serrano@duke.edu. 